Supplement of The Cryosphere, 12, 3923-3930, 2018

https://doi.org/10.5194/tc-12-3923-2018-supplement

(C) Author(s) 2018. This work is distributed under

the Creative Commons Attribution 4.0 License.

(c) (1)

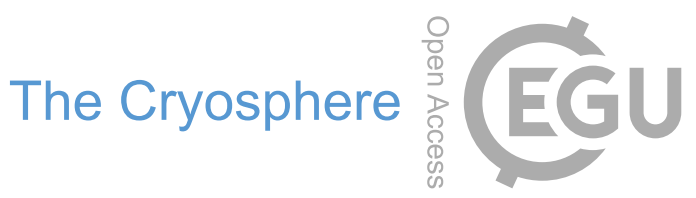

Supplement of

\title{
Brief communication: An ice surface melt scheme including the diurnal cycle of solar radiation
}

Uta Krebs-Kanzow et al.

Correspondence to: Uta Krebs-Kanzow (uta.krebs-kanzow@awi.de)

The copyright of individual parts of the supplement might differ from the CC BY 4.0 License. 


\section{Mean surface temperture and wind speed of melt periods from observations}

$T_{a}$ is the monthly mean temperature and thus also includes temperatures outside of the daily melt period. The strategy in our paper is to only consider that part of the day, when the ice is warm enough to melt. We thus need to estimate the mean temperature during this melt period. To illuminate the relation between $T_{a}$ and $T_{M P}$, we analyzed hourly climate data from 5 PROMICE (?) weather stations: $2 \mathrm{~m}$ air temperature $T_{a}$, surface temperature $T_{\text {surf }}$, albedo A and short wave radiation SW. In analogy to the dEBM, we determine the melt period for each month by identifying those hours which comply with the conditions

$$
\overline{(1-A) S W}>71.9 W m^{-2}
$$

and

$10 \overline{T_{\text {surf }}}>-0.01^{\circ} \mathrm{C}$

. The bars denotes hourly data taken from the monthly mean diurnal cycle. We analyzed 18 PROMICE stations which cover a period of up to ten years (2008-2017) and identified 390 monthly mean diurnal cycles which exhibit a melt period acording to our above definition. We don't need to resort to a minimum elevation angle here, as hourly radiation is available. Likewise the background melting condition is replaced by the condition, that hourly surface temperature data must be near melting point.

15 Indeed, the PROMICE data indicate that PDD is quite a good proxy for the monthly mean temperature of the melt period $T_{M P}$. Using a constant standard deviation of $3.5^{\circ} \mathrm{C}$ exhibits a particularly good fit (Fig. S1).

Furthermore analyzing the mean wind speed during the above melt periods, we find on average a wind speed of $u_{M P}=$ $3.8 \mathrm{~ms}^{-1}$ (Fig. S2). 


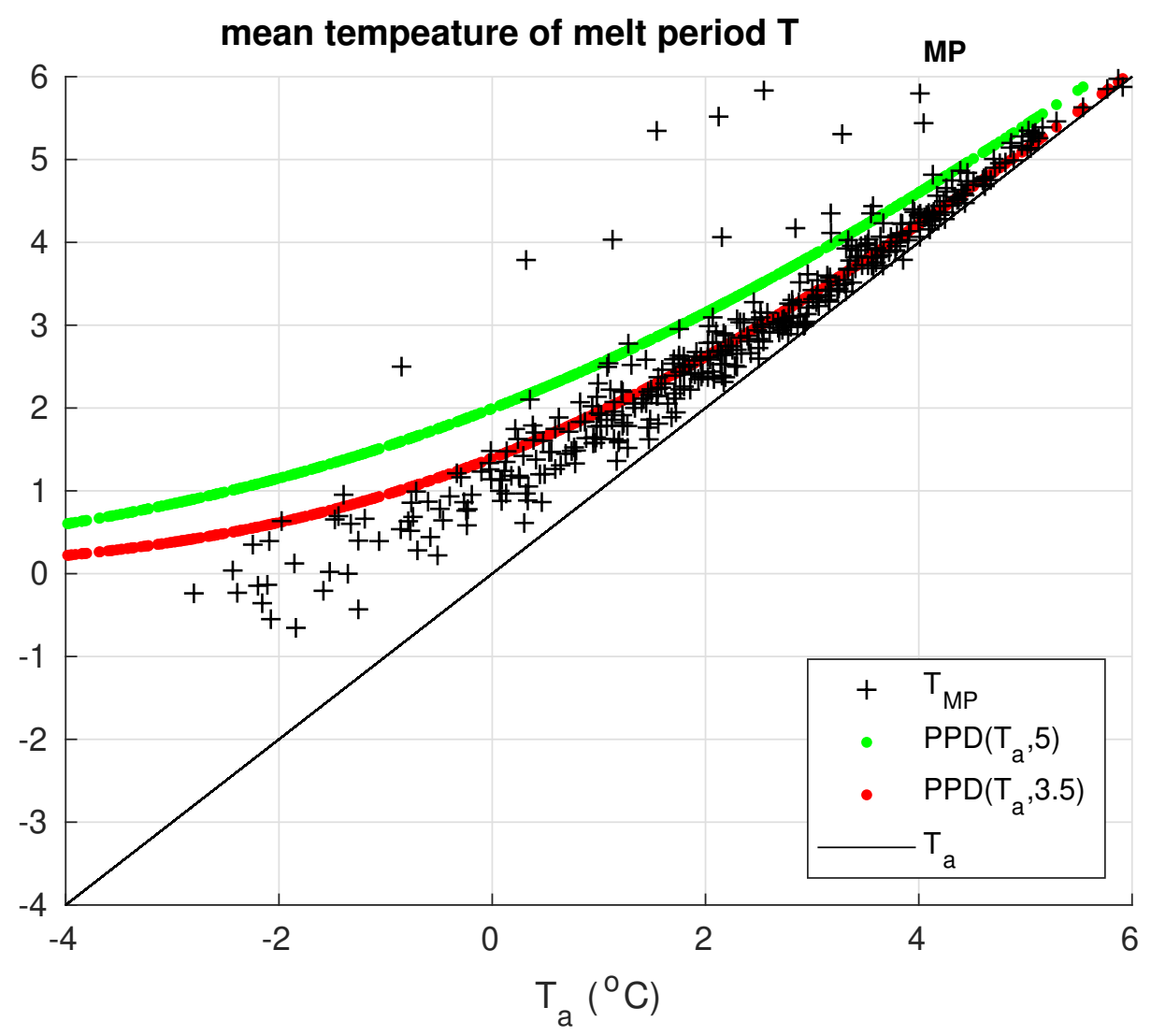

Figure S1. Monthly mean melt period temperature $T_{M P}$ and PDDs as functions of monthly mean near surface air temperature $T_{a}$. Crosses reflect monthly mean $T_{M P}$ as calculated from hourly near surface air temperature data of 18 PROMICE stations. Red and green points reflect PDD calculated from $T_{a}$ assuming a constant standard deviation of $3.5^{\circ} \mathrm{C}$ and $5^{\circ} \mathrm{C}$ respectively. 


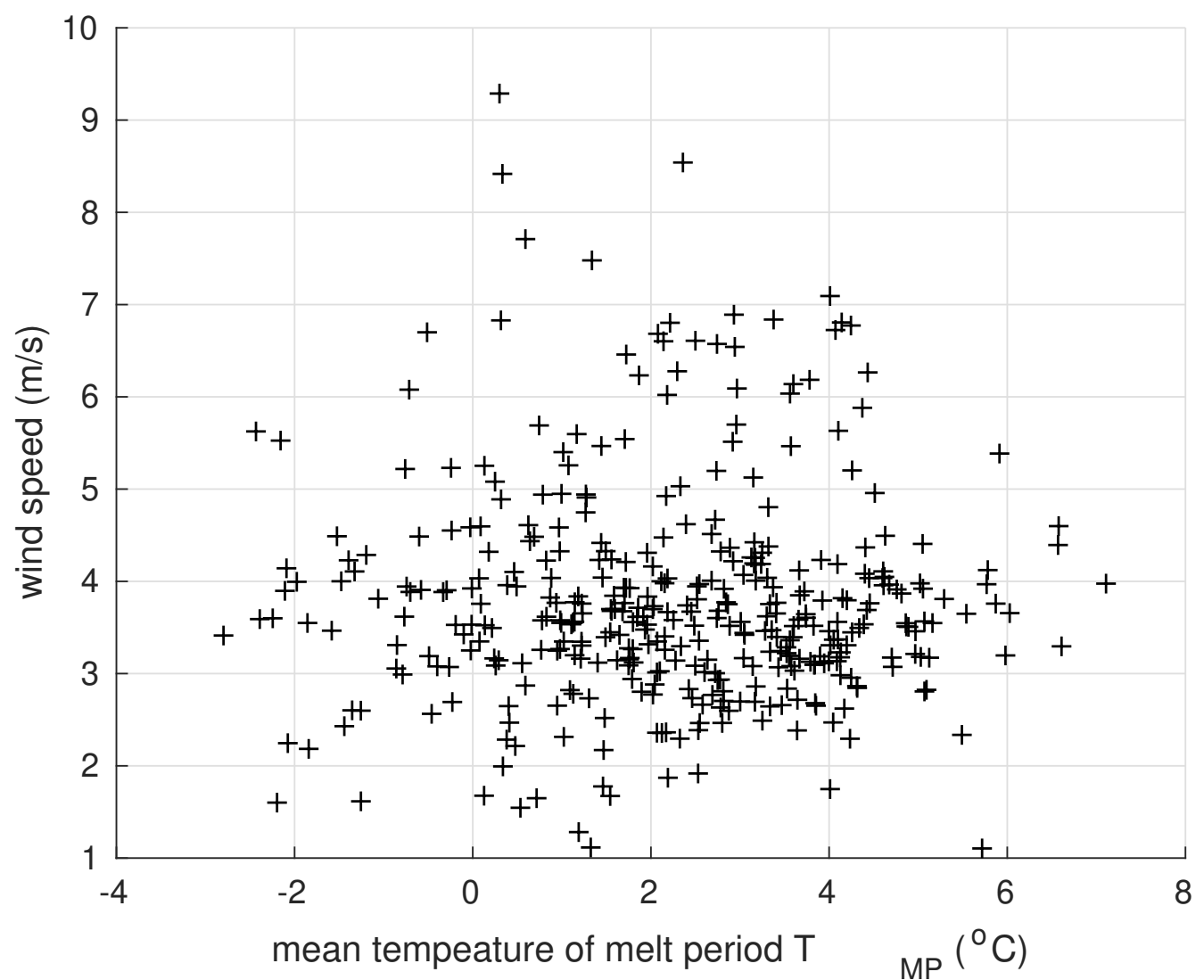

Figure S2. Monthly mean wind speed during melt periods $u_{M P}$ as a function of monthly mean near surface air temperature $T_{a}$. 

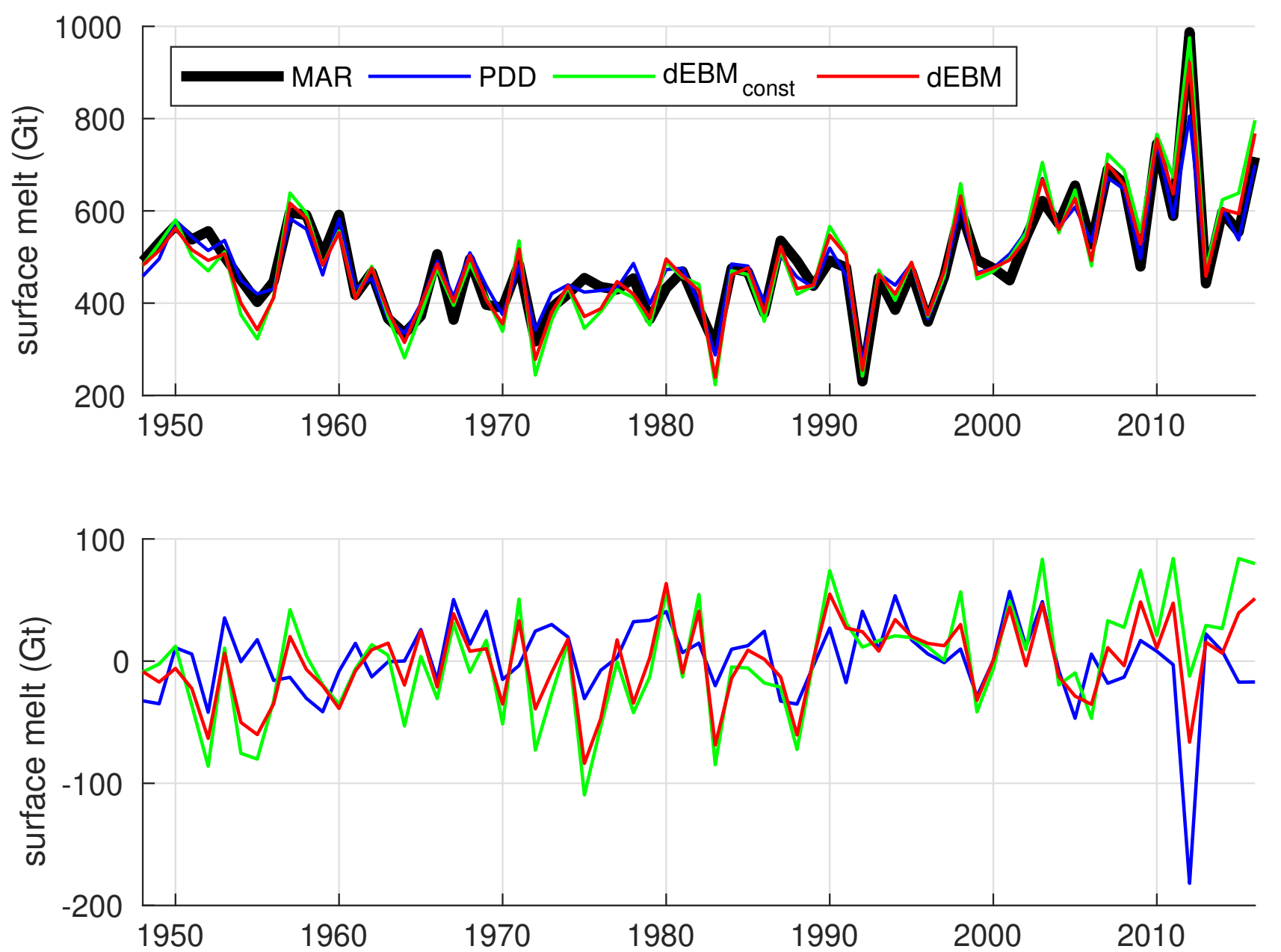

Figure S3. Upper panel: total yearly surface melt of the years 1948-2016 from MAR (black) and as predicted a) Total Greenland surface melt from 1948 to 2016 as simulated by MAR (black) and predicted from PDD-scheme (blue), $d E B M_{C O N S T}$ (green) and dEBM (red). Lower panel: yearly bias of total yearly surface melt predicted by PDD-scheme (blue), $d E B M_{C O N S T}$ (green) and dEBM (red) for the $1948-2016$ period relative to MAR. 